\title{
Patterns of antenatal care in low- versus high-risk pregnancies in Lebanon
}

F. El-Kak, ${ }^{1}$ M. Chaaya, ${ }^{2}$ O. Campbel/ ${ }^{3}$ and A. Kaddour ${ }^{1}$

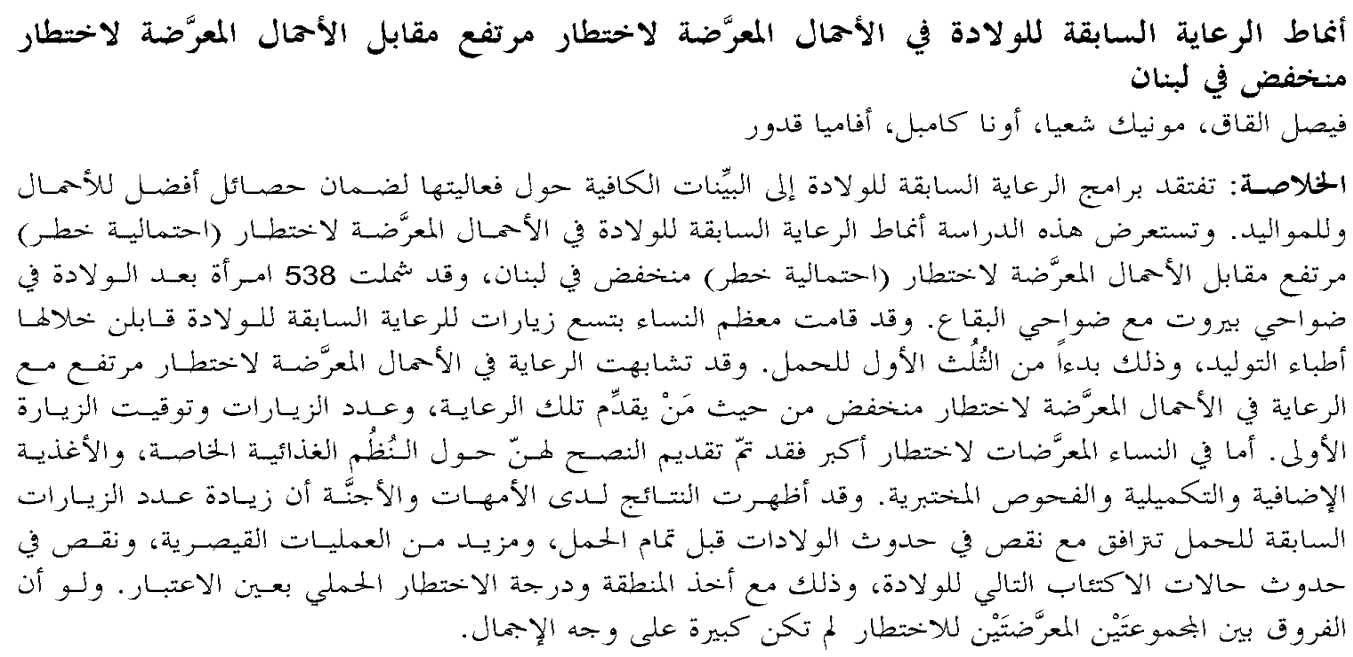

ABSTRACT We studied patterns of antenatal care in low- versus high-risk pregnancies in Lebanon comparing 538 women after delivery in urban Beirut with rural Baka'a. Most women had 9 antenatal care visits with an obstetrician, starting in the first trimester. Care for high-risk and low-risk pregnancies was similar in terms of type of provider, number of visits and timing of first visit. More high-risk women had advice about special diets, supplements and laboratory tests. Maternal and fetal outcomes showed that, controlling for area and pregnancy risk, more antenatal visits were associated with fewer preterm deliveries, more caesarean sections and fewer cases of postpartum depression. Overall, differences between risk groups were small.

\begin{abstract}
La surveillance prénatale dans les grossesses à bas risque par rapport aux grossesses à haut risque au Liban

RESUME Cette étude a examiné la surveillance prénatale dans les grossesses à bas risque par rapport aux grossesses à haut risque au Liban en comparant 538 femmes après l'accouchement dans la ville de Beyrouth et dans la Bekaa rurale. La majorité des femmes avaient effectué neuf consultations prénatales chez un obstétricien à partir du premier trimestre de la grossesse. La surveillance pour les grossesses à bas et à haut risque était similaire eu égard au type de prestataire, au nombre de consultations et au moment de la première consultation. Les femmes à haut risque étaient plus nombreuses à avoir reçu des conseils concernant les régimes alimentaires particuliers, les suppléments et les examens de laboratoire. L'issue pour la mère et le fœtus a montré que, en tenant compte de la zone et du niveau de risque de la grossesse, un plus grand nombre de consultations prénatales étaient associées à un nombre plus faible d'accouchements prématurés, à un plus grand nombre de césariennes et à un nombre plus faible de cas de dépression du post-partum. Dans l'ensemble, les différences entre les groupes à risque étaient peu importantes.
\end{abstract}

${ }^{1}$ Department of Health Behaviour and Education; ${ }^{2}$ Department of Epidemiology and Biostatistics, Faculty of Health Sciences, American University of Beirut, Beirut, Lebanon.

${ }^{3}$ Infectious Disease and Epidemiology Unit, London School of Hygiene and Tropical Medicine, London, United Kingdom.

Received: 26/03/02; accepted: 16/03/03

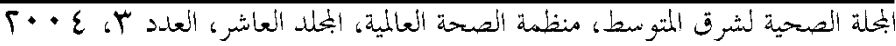




\section{Introduction}

Current antenatal care (ANC) programmes originate from patterns that were developed and practised in the early twentieth century. Since then, their core content has remained unchanged except for the introduction of certain new technologies due to advances in medical knowledge in industrialized countries. Unfortunately, the bulk of the content of ANC programmes is based on tradition rather than on solid evidence of effectiveness linking them to better pregnancy and baby outcomes. This was first recognized by Cochrane who recommended the investigation of antenatal care practices [1]. More recently, the US Public Health Service Expert Panel on the Content of Prenatal Care noted that many of the studies conducted to evaluate existing ANC lacked scientific rigour [2]. Only lately have ANC programmes been subjected to rigorous criticism and review to try to design new programmes that are cost-effective in terms of quality of care, client satisfaction and health care service competencies and that improve obstetric and neonatal outcomes [3].

In an attempt to look at the various elements of ANC (such as frequency of visits, content, providers and pregnancy outcomes), several studies have shown that new models can be introduced without risk to maternal or prenatal outcomes. A randomized controlled trial conducted in Zimbabwe, a developing country, showed that a major reduction in the number of visits was compatible with good perinatal outcomes and lower cost [4]. In the WHO systemic review of randomized controlled trials of routine ANC, the research group showed that a reduction in the number of ANC visits could be possibly introduced into clinical practice without harmful ef- fects on the mother or the baby [5]. Specifically, the WHO ANC trial research group tested a new model of routine ANC visits which did not affect maternal and perinatal outcomes [6]. In addition, there is a continuing debate concerning the optimal provider - an obstetrician or a midwifefor routine prenatal and intrapartum care for low-risk pregnant women [7-9].

In the Middle East region, less than 70\% of pregnant women receive some form of antenatal care [10]. Lebanon, a Middle Eastern developing country, has a health care system that is highly medicalized and expensive. In Lebanon, antenatal care is mostly provided by obstetricians according to the model of industrialized countries, in the absence of any standard guidelines or evidence-based practices. Data from a national survey on maternal and child health in 1996 revealed that in the previous 5 years around $87 \%$ of pregnant women received antenatal care [11]. The obstetrician provided antenatal care for $93 \%$ of them, and supervised $80 \%$ of the deliveries compared with $16 \%$ of deliveries supervised by midwives. Despite these favourable indicators, the maternal mortality rate in Lebanon is 104 per 100000 live births.

The content of antenatal care in terms of number of visits, quality of care, health care provider and other constituents had never been investigated in local surveys in Lebanon. This study aimed to provide a descriptive profile of antenatal care practices in terms of the frequency and content of visits and the type and practice of the provider. It also compared the patterns of antenatal care according to geographical area (Beirut versus Beka'a) and whether the pregnancy was low-risk or high-risk. Furthermore, the study investigated the association of ANC practices with maternal and fetal outcomes.

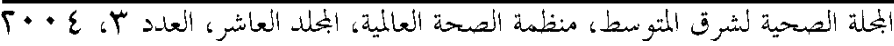




\section{Methods}

This was a secondary analysis of a prospective investigation of women delivering in selected hospitals in 2 areas in Lebanon: the capital city, Beirut, and a rural agricultural area $60 \mathrm{~km}$ away from Beirut, Beka'a. The investigation comprised 2 phases. In the first phase, all women in the maternity wards of 9 hospitals who delivered in the period October 1997-October 1998, and who gave their consent, were asked to respond to a questionnaire within 24 hours of delivery. None refused to participate. Women were then interviewed a second time in their homes 2-3 months later. A total of 538 women completed the first interview, of whom 396 were followed up (giving a follow-up rate of $74 \%$ overall: $68 \%$ in Beirut and $80 \%$ in the Beka'a area).

Data were collected through face-toface interviews using a structured questionnaire. Interviewers were midwives in the surveyed hospitals who received a 2day training and were supervised closely. The questions on prenatal care included the time of the first antenatal visit, frequency of visits, and the type of health care provider chosen. Questions were asked about the content of antenatal care offered, including laboratory tests, diet and exercise recommendations (which varied for low-risk and high-risk women) and whether women adhered to the above recommendations. The questionnaire also addressed aspects of the newborn baby, the occurrence of certain postpartum symptoms, delivery care practices, the course of the current pregnancy and the presence of medical conditions during pregnancy. The number of prenatal visits was divided into 3 categories: 1-4, 59 and $10+$ visits. A high-risk pregnancy was defined as one where the mother had a chronic medical condition or a pregnancycomplicated medical condition: reported di- abetes, high blood pressure, cardiovascular problem, renal problem, epilepsy, asthma, recurrent previous abortions (4 or more) or a stillbirth. Low-risk pregnancy was one that did not have any of these conditions. Fetal outcome was assessed by the presence of at least 1 neonatal problem (yes or no). A total of 64 mothers $(11.9 \%)$ reported congenital malformations, stillbirth, jaundice, hypoxia or blue baby syndrome. Three variables were selected to assess maternal outcomes: gestational age (preterm or term), type of delivery (vaginal or caesarean section) and postpartum depression (yes or no).

\section{Statistical analysis}

The variables measuring prenatal outcome were classified by area (Beirut versus Beka'a) and by pregnancy risk (low versus high risk). Furthermore, selected fetal and maternal outcomes were compared by number of prenatal visits categorized as 14, 5-9 and 10+ visits in each geographical area. The chi-squared test was used to check for statistically significant differences between the 2 areas and 2 types of pregnancy risk and the number of antenatal visits with the selected prenatal variables and pregnancy outcome variables.

\section{Results}

A total of 538 women were surveyed: 303 residing in the capital Beirut and 235 in Beka'a. Overall, the 2 groups had different sociodemographic characteristics (Table 1). Women residing in Beirut had a statistically significant higher level of education and more of them were working (with part of their employment outside the house) compared with women residing in the rural areas, though the latter women may have been doing work without pay on the family

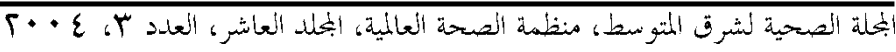


farm in addition to their work at home. The Beka'a women were also younger than those in Beirut (mean age 27.4 versus 28.8 years) and had married earlier (19.7 versus 22.7 years). A higher proportion of the women in Beka'a were multiparous (74.9\% versus $66.0 \%$ ). Differences between the 2 areas were statistically significant.

The great majority of women in the 2 areas had attended ANC (95.0\% overall), with almost all women in Beirut having received ANC (99.7\%) compared with $88.9 \%$ in the Beka'a (Table 2). The obstetrician was the most commonly reported provider of care in both areas $(94.7 \%)$, but more so in Beirut (99.7\% versus $87.6 \%$ ). Other providers of care were midwives, traditional birth attendant (TBAs) (only in Beka'a) and other health personnel. More women in the rural area received antenatal

\begin{tabular}{|c|c|c|c|}
\hline Characteristic & $\begin{array}{c}\text { Area of } \\
\text { Beirut } \\
(n=303)\end{array}$ & $\begin{array}{c}\text { esidence } \\
\text { Beka'a } \\
(n=235)\end{array}$ & $\begin{array}{c}\text { Total } \\
(n=538) \\
\%\end{array}$ \\
\hline \multicolumn{4}{|l|}{ Parity } \\
\hline Primiparous & 34.0 & 25.1 & 30.1 \\
\hline Multiparous & 66.0 & 74.9 & 69.9 \\
\hline \multicolumn{4}{|l|}{ Educational level } \\
\hline Illiterate & 2.6 & 9.4 & 5.6 \\
\hline Read and write & 1.3 & 3.0 & 2.0 \\
\hline Elementary & 12.2 & 22.1 & 16.5 \\
\hline Intermediate & 25.4 & 40.0 & 31.8 \\
\hline Secondary & 19.5 & 17.0 & 18.4 \\
\hline University & 28.7 & 8.1 & 19.7 \\
\hline Technical & 10.2 & 0.4 & 5.9 \\
\hline \multicolumn{4}{|l|}{$\begin{array}{l}\text { Working during } \\
\text { pregnancy }\end{array}$} \\
\hline Yes & 28.0 & 6.0 & 18.0 \\
\hline No & 72.0 & 94.0 & 82.0 \\
\hline
\end{tabular}

$\mathrm{n}=$ total number of women. care from a midwife $(9.6 \%)$, compared with less than $1 \%$ in Beirut. The first antenatal visit took place in the first trimester for the majority of women $(87.5 \%)$, with a mean number of visits of 8.93 . Women in the Beka'a made fewer visits (mean $6.0 \pm$ standard deviation 5.1) compared with women in Beirut $(10.0 \pm 3.9)$ but the highest proportion in both $(46.0 \%)$ made between 5 and 9 visits (Table 2).

As for the content of the antenatal visit, a substantial proportion of women in the sample were requested to do regular laboratory tests and to take iron, folic acid and vitamin supplements (Table 2), significantly more of them in Beirut. One-third of women were given diet recommendations, and only around $6 \%$ were given exercise advice, with no significant differences between the 2 areas. Women complied with intake of vitamins and minerals and laboratory tests, but less so with exercise and diet. The extent of adherence was similar in both areas, except for diet where more women in Beirut complied with diet recommendations compared with women in Beka'a, and this was statistically significant.

Comparing different types of providers (obstetrician versus midwives/TBA or others) showed that the pattern of ANC varied with respect to frequency of visits, advice about supplements and laboratory examinations, and was similar with respect to other aspects of ANC. Women who visited obstetricians were more likely to be asked to have laboratory tests (data not shown).

A total of $176(32.7 \%)$ women surveyed in the 2 areas had a high-risk pregnancy (information was missing for 1 woman). Table 3 shows that the high-risk and low-risk groups had a similar pattern of $\mathrm{ANC}$ in terms of type of provider, number of visits and timing of first visit, although significantly more high-risk than low-risk

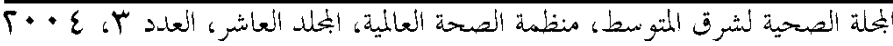


Table 2 Distribution of study women by antenatal care and area of residence

\begin{tabular}{|c|c|c|c|}
\hline $\begin{array}{l}\text { Antenatal care } \\
\text { indicator }\end{array}$ & $\begin{array}{c}\text { Area of } \\
\text { Beirut } \\
(n=303) \\
\%\end{array}$ & $\begin{array}{c}\text { residence } \\
\text { Beka'a } \\
(n=235) \\
\%\end{array}$ & $\begin{array}{c}\text { Total } \\
(n=538) \\
\%\end{array}$ \\
\hline \multicolumn{4}{|l|}{ Attended antenatal } \\
\hline \multicolumn{4}{|l|}{ Care provider } \\
\hline Obs/gyn & 99.7 & 87.6 & 94.7 \\
\hline Midwife & 0.3 & 9.6 & 4.1 \\
\hline TBA & 0 & 1.4 & 0.6 \\
\hline Other & 0 & 1.4 & 0.6 \\
\hline \multicolumn{4}{|l|}{ Trimester of first visit } \\
\hline $1 \mathrm{st}$ & 88.7 & 85.6 & 87.5 \\
\hline 2nd & 7.6 & 8.6 & 8.0 \\
\hline 3rd & 3.6 & 5.7 & 4.5 \\
\hline \multicolumn{4}{|l|}{ No. of visits ${ }^{* *}$} \\
\hline $1-4$ & 5.0 & 43.1 & 20.5 \\
\hline $5-9$ & 45.7 & 46.4 & 46.0 \\
\hline $10+$ & 49.3 & 10.5 & 33.5 \\
\hline \multicolumn{4}{|l|}{$\begin{array}{l}\text { Care/treatment } \\
\text { recommended }\end{array}$} \\
\hline \multicolumn{4}{|l|}{ Diet } \\
\hline Yes & 30.1 & 34.1 & 31.8 \\
\hline No & 69.9 & 65.9 & 68.2 \\
\hline \multicolumn{4}{|l|}{ Vitamins/minerals** } \\
\hline Yes & 97.7 & 87.5 & 93.5 \\
\hline No & 2.3 & 12.5 & 6.5 \\
\hline \multicolumn{4}{|l|}{ Laboratory tests** } \\
\hline Yes & 98.0 & 57.7 & 81.6 \\
\hline No & 2.0 & 42.3 & 18.4 \\
\hline \multicolumn{4}{|l|}{ Exercise } \\
\hline Yes & 7.0 & 3.9 & 5.7 \\
\hline No & 93.0 & 96.1 & 94.3 \\
\hline \multicolumn{4}{|l|}{$\begin{array}{l}\text { Compliant with care/ } \\
\text { treatment }\end{array}$} \\
\hline \multicolumn{4}{|l|}{ Diet } \\
\hline No & 7.7 & 21.1 & 13.6 \\
\hline Sometimes & 35.2 & 12.7 & 25.3 \\
\hline Most of the time & 57.1 & 66.2 & 61.1 \\
\hline \multicolumn{4}{|l|}{ Vitamins } \\
\hline No & 3.9 & 3.8 & 3.9 \\
\hline Sometimes & 17.7 & 12.6 & 15.7 \\
\hline Most of the time & 78.4 & 83.5 & 80.4 \\
\hline
\end{tabular}

\begin{tabular}{|c|c|c|c|}
\hline $\begin{array}{l}\text { Antenatal care } \\
\text { indicator }\end{array}$ & $\begin{array}{c}\text { Area of } \\
\text { Beirut } \\
(n=303) \\
\%\end{array}$ & $\begin{array}{c}\text { residence } \\
\text { Beka'a } \\
(n=235) \\
\%\end{array}$ & $\begin{array}{c}\text { Total } \\
(n=538) \\
\%\end{array}$ \\
\hline \multicolumn{4}{|l|}{ Laboratory tests } \\
\hline No & 1.4 & 4.2 & 2.2 \\
\hline Sometimes & 2.8 & 4.2 & 3.2 \\
\hline Most of the time & 95.8 & 91.7 & 94.6 \\
\hline \multicolumn{4}{|c|}{ Exercise } \\
\hline No & 19.0 & 12.5 & 17.2 \\
\hline Sometimes & 14.3 & 25.0 & 17.2 \\
\hline Most of the time & 66.7 & 62.5 & 65.5 \\
\hline
\end{tabular}

pregnant women attended antenatal care. Some differences were found in the content of care, with significantly more women with high-risk pregnancies being recommended to have a special diet, to take vitamins and minerals and to do laboratory tests. Yet the differences between the 2 groups were not substantial and there were no significant differences between the groups in terms of compliance with advice, because the numbers in the 2 groups were very small and were re-categorized into compliant and non-compliant.

Tables 4 and 5 show the association between the number of ANC visits and selected maternal and fetal outcomes reported by the women who attended ANC, according to area of residence and pregnancy risk group. Increased number of visits were associated with fewer cases of postpartum depression among high-risk women and those residing in Beirut, and fewer preterm deliveries only for women in Beirut. A higher proportion of deliveries by caesarean

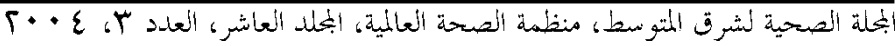




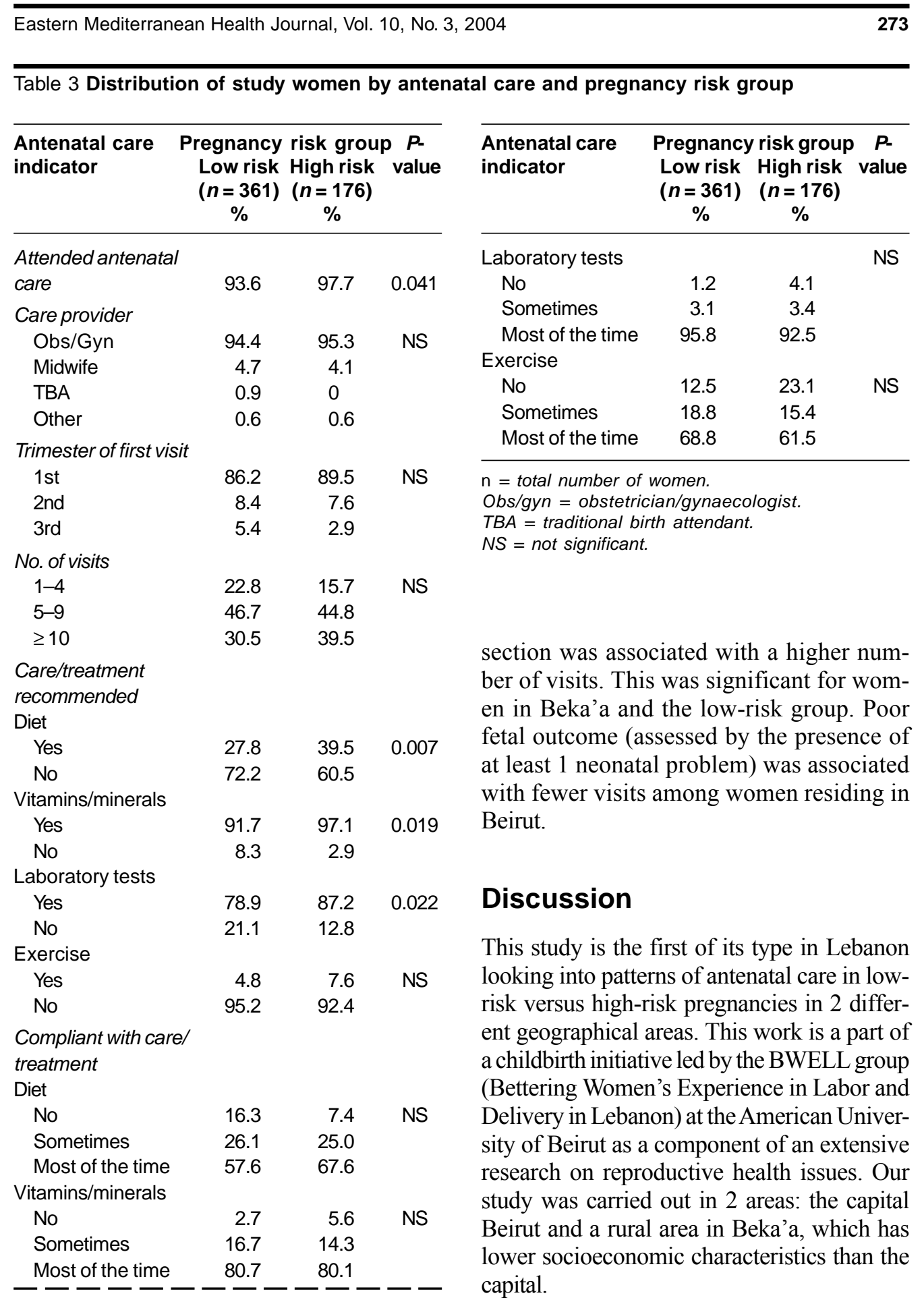

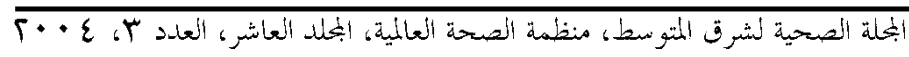




\begin{tabular}{|c|c|c|c|c|c|}
\hline \multirow{2}{*}{$\begin{array}{l}\text { Risk group/No. } \\
\text { of ANC visits }\end{array}$} & \multirow{2}{*}{$\begin{array}{l}\text { No. of } \\
\text { women }\end{array}$} & \multirow[b]{2}{*}{$\begin{array}{c}\text { Problem for } \\
\text { newborn } \\
\%\end{array}$} & \multicolumn{2}{|c|}{ Outcome } & \multirow[b]{2}{*}{$\begin{array}{c}\text { Postpartum } \\
\text { depression }^{a} \\
\%\end{array}$} \\
\hline & & & $\begin{array}{c}\text { Preterm } \\
\text { delivery } \\
\%\end{array}$ & $\begin{array}{c}\text { Caesarean } \\
\text { delivery } \\
\%\end{array}$ & \\
\hline \multicolumn{6}{|l|}{ Low risk } \\
\hline $1-4$ visits & 77 & 10.4 & 5.6 & 14.3 & 23.4 \\
\hline $5-9$ visits & 158 & 8.2 & 6.4 & 31.0 & 24.6 \\
\hline \multirow[t]{2}{*}{$\geq 10$ visits } & 103 & 9.7 & 5.8 & 27.2 & 14.5 \\
\hline & & $P=0.84$ & $P=0.97$ & $P=0.02$ & $P=0.22$ \\
\hline \multicolumn{6}{|l|}{ High risk } \\
\hline $1-4$ visits & 27 & 22.2 & 14.8 & 29.6 & 38.9 \\
\hline $5-9$ visits & 77 & 14.3 & 10.5 & 28.6 & 22.0 \\
\hline \multirow[t]{2}{*}{$\geq 10$ visits } & 68 & 16.2 & 4.4 & 33.8 & 11.4 \\
\hline & & $P=0.63$ & $P=0.21$ & $P=0.78$ & $P=0.049$ \\
\hline
\end{tabular}

a Only for 396 women who were followed up 3-5 months after delivery.

The characteristics of the 2 study populations were as expected. The study was not representative of all women delivering in these areas because subjects were recruited at hospital delivery, but it captured most women since $95 \%$ and $92 \%$ of deliv- eries in Beirut and Beka'a respectively occur in health care delivery facilities [10]. The study confirmed the notion that most women in the 2 areas seek antenatal care early in gestation (first trimester), and mainly through obstetricians as the pre-

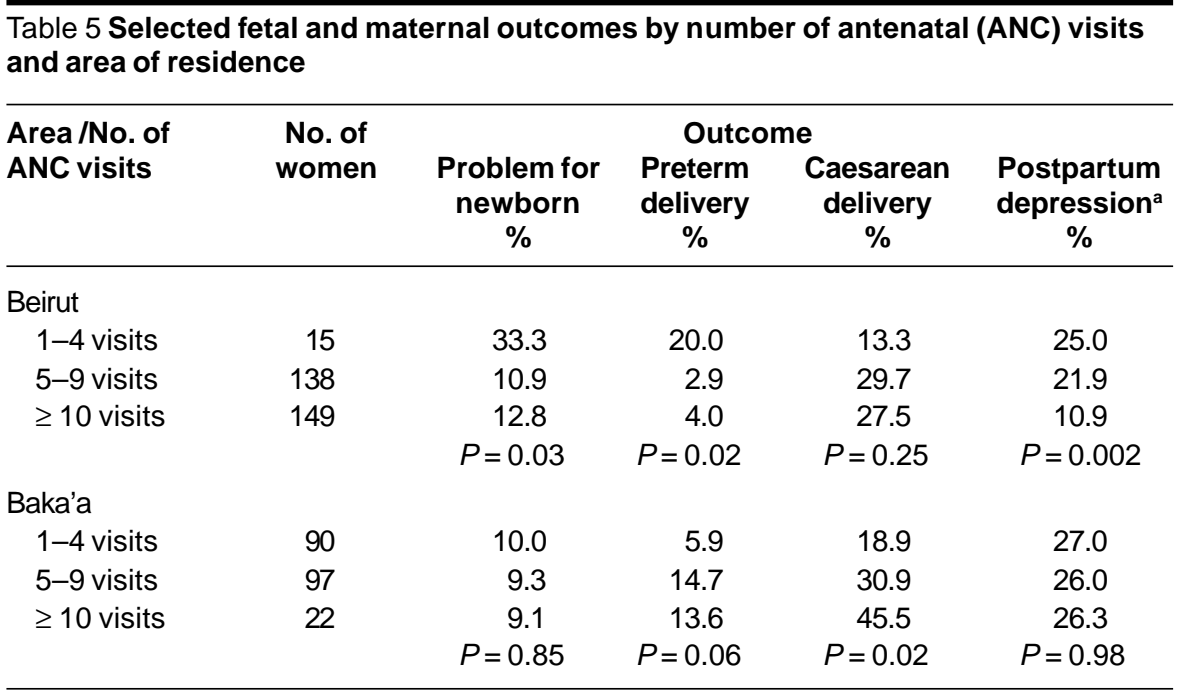

a Only for 396 women who were followed up 3-5 months after delivery.

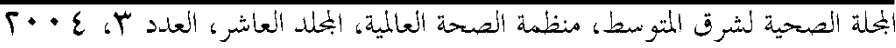


ferred provider. This confirms the preference for medical-led pregnancy care in Lebanon, even though midwives remain the preferred caregivers by some women in rural areas for sociocultural, financial and personal reasons. It can be argued that the over-medicalization of pregnancy care, the type of existing health care system, overwhelming number of obstetricians, and client perceptions of medical-led antenatal care are all possible reasons favouring medical-led over midwife-led antenatal care.

Moreover, further examination of the patterns of care in Beirut compared with Beka'a showed that, although medical-led care is more established in urban areas than rural ones (more obstetricians, better livelihoods, less traditional lifestyles), there was no significant difference between the 2 areas with regard to the antenatal package. Women in Beirut made more ANC visits than women in the Beka'a (an average of 10 versus 6), leading to additional recommendations such as more laboratory tests, vitamins, exercise and diet instructions. Concerning maternal and neonatal outcomes, our data suggest that additional visits might have a protective effect. These visits allowed earlier and better detection of possible obstetric (maternal) and psychosocial problems, and consequently better management, that resulted in fewer cases of depression or preterm delivery, better neonatal outcomes, and more caesarean sections. This was contingent upon woman's risk and area of residence. The degree of client adherence was similar in both patterns of visits (except for diet where more of the Beirut women adhered compared with Beka'a), suggesting that additional visits may not have affected women's health behaviour in pregnancy or improved client-provider communication.
Regarding antenatal care for low-risk versus high-risk pregnancies, there was no significant difference in the frequency of visits, content of the antenatal package, or any additional specific recommendations in both categories of women (Beirut and Beka'a) and by both providers. Although one would expect to find a different antenatal model for high-risk cases, this was not revealed in the study. This could be due to several factors. High-risk cases were identified based on self-reporting of women about their medical conditions, even though there were no specific antenatal care measures. Antenatal care is not standardized and there are no available guidelines strictly followed in different pregnancy conditions, and so the most convenient antenatal care model remains to be implemented.

These findings call for a serious consideration of existing pregnancy care practices in Lebanon, in terms of the essential elements in the antenatal care package (frequency and content of visits) and the providers of care. These should be relevant to the risk type of each pregnancy in order to ensure quality care, economic effectiveness, good perinatal outcomes, and women's satisfaction. This necessitates a re-consideration of existing antenatal care practices through an in-depth investigation of their content. It is expected to lead towards adoption of an antenatal model that is scientifically demonstrated to be effective and have a good impact on outcomes. At the same time, clients should be educated about high-risk pregnancy conditions and about the appropriate measures and recommendations to be followed.

Additional research work is needed to address the lack of information and indepth analysis in the current study and to assess the efficacy of the existing pregnancy care programmes in Lebanon in

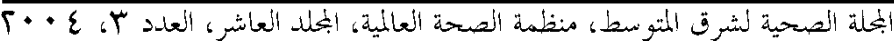


terms of number of visits, type of provider, pregnancy risk, client perception and satisfaction and clinical outcomes. This re- search should be based on the evidence from a growing number of evaluations of new models of antenatal care.

\section{References}

1. Cochrane AL. Effectiveness and efficiency-random reflections on health services. Cambridge, Cambridge University Press, 1989.

2. Rosen M, Merkatz I, Hill J. Caring for our future: a report by the expert panel on the content of prenatal care. Obstetrics and gynecology, 1991, 77:782-7.

3. Ba'aqueel H. World Health Organization randomized antenatal care trial. In: Ottesen B, Tabor A, eds. New insights in gynaecology and obstetrics: research and practice. Carnforth, New York, Parthenon, 1998.

4. Munjanja SP, Lindmark G, Nystrom L. Randomized controlled trial of a reduced-visits programme of antenatal care in Harare, Zimbabwe. Lancet, 1996, 348:364-9.

5. Carroli G et al. WHO systematic review of randomized controlled trials of routine antenatal care. Lancet, 2001, 357:1565.

6. Villar $\mathrm{J}$ et al. WHO antenatal care randomized trial for the evaluation of a new model of routine antenatal care. Lancet, 2001, 357:1551.
7. Tucker JS et al. Should obstetricians see women with normal pregnancies? A multicentre randomized controlled trial of routine antenatal care by general practitioners and midwives compared with shared care led by obstetricians. British medical journal, 1996, 312:5549.

8. Turnbull D et al. Randomized controlled trial of efficacy of midwife-managed care. Lancet, 1996, 348:213-8

9. Villar J, Khan-Neelofur D. Patterns of routine antenatal care for low-risk pregnancy (Cochrane Review). In: The Cochrane library, issue 4. Oxford, Update Software, 1999.

10. Demographic and health indicators for countries of the Eastern Mediterranean. Alexandria, Egypt, WHO Eastern Mediterranean Regional Office, 1997.

11. Pan Arab Project for Child Development (PAPCHILD). Lebanon maternal and child health survey, 1966. Summary report. Beirut, Lebanon, Ministry of Public Health, 1998. 